\title{
Habitat selection and shelter use by Octopus tetricus
}

\author{
Tara J. Anderson* \\ Leigh Marine Laboratory and School of Biological Sciences, University of Auckland, PO Box 349, Warkworth, New Zealand
}

\begin{abstract}
The ecology of a shallow-water benthic octopus (Octopus tetricus) in northeastern New Zealand was examined. Spatial and temporal patterns of abundance, habitat association, and shelter use were quantified. Octopus were abundant on the reef during summer, during which time females brooded eggs. Numbers declined rapidly at the end of summer Octopus were not evenly distributed across sites, and were more abundant in patch reef habitats than in broken or flat reef habitats. The role of reefal factors in habitat selection, both abiotic and biotic, was examined using multiple regression and partial correlation analyses. Octopus were more abundant near the reef edge, and in areas with high numbers of small boulders. No relationshıps between octopus and potential reefal predators (eels) or reefal prey (crayfish) species were found. Soft-sediment bivalves occurred in the majority of shelter middens, suggesting that octopus were foraging over adjacent soft-sediments rather than on the rocky reef itself. The degree of shelter modification varied with habitat, sex, and brooding status. Shelters were more likely to be modified in patch reef habitats than in broken and flat reef habitats. Brooding females were more likely to modify their shelters than non-brooding females and males, and often completely barncaded shelter entrances. This study suggests that Octopus tetricus are associated with rocky reef habitats during the breeding season, while a considerable portion of their life may be spent in soft-sediment habitats.
\end{abstract}

KEY WORDS: Habitat association - New Zealand Octopus tetricus Rocky Reef Shelters

\section{INTRODUCTION}

Shallow benthic octopus are found commonly throughout the world, and are likely to be an important component of many ecological communities. Limited research on octopus distribution patterns suggests that many species are characterised by marked density fluctuations at particular sites (Hartwick \& Thorarinsson 1978, Ambrose 1982) and strong site selection (Mather \& O'Dor 1991). The abundances of several octopus species vary through time (Mangold-Wirz 1963, Mangold 1983, Ambrose 1988). Both ontogenetic and migratory mechanisms have been suggested to be responsible for these patterns. Octopus may exert considerable choice in food and shelters (Yarnell 1969, Wells 1978, Aronson 1986, Voight 1988) and appear to

\footnotetext{
- Present address: Department of Zoology, The University of Melbourne, Parkville, Victoria 3052, Australia.

E-mail: tara.anderson@zoology.unimelb.edu.au
}

have a clear 'idea' of what constitutes a preferred shelter-often actively modifying shelters (Ambrose 1982, Mather 1988). The dynamics of habitat association in octopus appear to be complex yet despite their importance to fisheries and potential influence on marine communities, octopus habitat use has received little rigorous attention. In this study I measure the spatial and temporal distribution and abundance of a shallowwater benthic octopus, Octopus tetricus (Gould, 1852), and the importance of fine scale habitat attributes in contributing to these patterns.

A number of habitat factors have been suggested to influence octopus distribution and abundance. In soft sediment habitats, which are generally featureless, small octopus are often associated with shells which comprise a large portion of the heterogeneity of the habitat (Mather 1982a, b, Mather \& O'Dor 1991, Voight 1992). On rocky reefs, octopus rely heavily on naturally occurring shelters for protection from predation (Hartwick \& Thorarinsson 1978, Ambrose 1982, Aron- 
son 1986, Hartwick et al. 1988, Mather \& O'Dor 1991) Shelter types utilised by octopus are variable and often opportunistic - ranging from naturally occurring holes and crevices (Hartwick et al. 1984b) to artificial shelterage within discarded car tyres, pipes, and railway iron (Russell 1971, author's pers, obs.). Many of these shelters are likely to limit the size of the occupant (Hartwick et al. 1984b).

Shelters in reefal habitats are often created or enhanced by excavation of loose material and by drawing boulders and debris up around the shelter entrance. This behaviour has been observed for many shallow-benthic octopus species (Octopus cyanea, Yarnell 1969; O. dofleini, Hartwick \& Thorarinsson 1978, Hartwick et al. 1981; O. bimaculatus, Ambrose 1982; O. vulgaris, Mangold 1983; O. cyanea, Van Heukelem 1983; O. briareus, Aronson 1986) The distribution of shelters and shelter material within reefal habitats may influence patterns of octopus abundance. However, Ambrose (1988) suggested that shelters did not appear to be limiting in reefal habitats. This is equivocal, and more formal studies are necessary.

Biological features of the reefal environment such as predator and prey distributions may also be important in explaining distribution and abundance patterns of octopus (Aronson 1986, 1989, Mather \& O'Dor 1991). Physical arm damage, such as partial or severe arm loss (Hartwick et al. 1978b, 1988, author's pers. obs.), and gut contents of many fish species (Mather 1992, author's pers. obs.) suggest that predatory attacks on octopus are common. Several studies have addressed the presence of potential predators (e.g. Hartwick \& Thorarinsson 1978, Ambrose 1988, Aronson 1989); however, few studies have quantified the relationship between octopus and their predators. Octopus feed on a wide range of prey species (Wodinsky 1969, Boyle 1983a, Ambrose 1984, author's pers. obs.) and will exhibit prey preferences (Wodinsky 1969, author's pers. obs.). Field studies to date, however, have found that Octopus diet is influenced by both food preferences and prey availability (Hartwick et al. 1981. Ambrose 1982). Hence, prey type and abundance are likely to influence distribution and abundance of octopus.

Octopus tetricus commonly occurs along the southeastern coast of Australia (T N. Stranks pers. comm.) and in the northern half of the North Island of New Zealand (Anderson 1994). Along the northeastern coast of New Zealand $O$. tetricus occurs commonly in reefal habitats, attaining sizes of up to $5 \mathrm{~kg}$. The nomenclature of this species will be assessed by Stranks, while a concise description of this species will be presented by Anderson. O. tetricus, during daylight hours, is largely sedentary and shelters in reef associated lairs. Although $O$. tetricus are considered cryptic, they can be readily located in reefal habitats by the distinctive orange colouration of their arms, funnel, and mantle opening and a slight recoil that many/most individuals exhibit as a diver passes over or close by.

The aims of this study were to measure and describe spatio-temporal dynamics and habitat association of Octopus tetricus on a northeastern New Zealand rocky reef. In addition I wished to determine which reefal habitat characteristics, both physical and biotic, may be responsible for these patterns. I quantified prey occurrence in shelter middens, shelter use and the relationship of shelter modification with sex and brooding status within the reefal population.

\section{METHODS}

Study site. This study was carried out in the Cape Rodney to Okakari Point Marine Reserve (hereafter the 'Marine Reserve') situated on the northeastern coast of northern New Zealand ( $36^{\circ} 16^{\prime} \mathrm{S}, 174^{\circ} 48^{\prime} \mathrm{E}$ ) (Fig. 1). The physical and biological environment of the Marine Reserve has been previously described (Gordon \& Ballantine 1976, Ayling 1981, Choat \& Schiel 1982). The Marine Reserve is composed of 2 basic rock types, sandstone and greywacke (Ayling 1978), and these influence the structure of the subtidal habitats available. Greywacke is more rugose and broken than sandstone (McCormick \& Choat 1987), and consequently contains little 'reef flat' habitat (Ayling 1978).

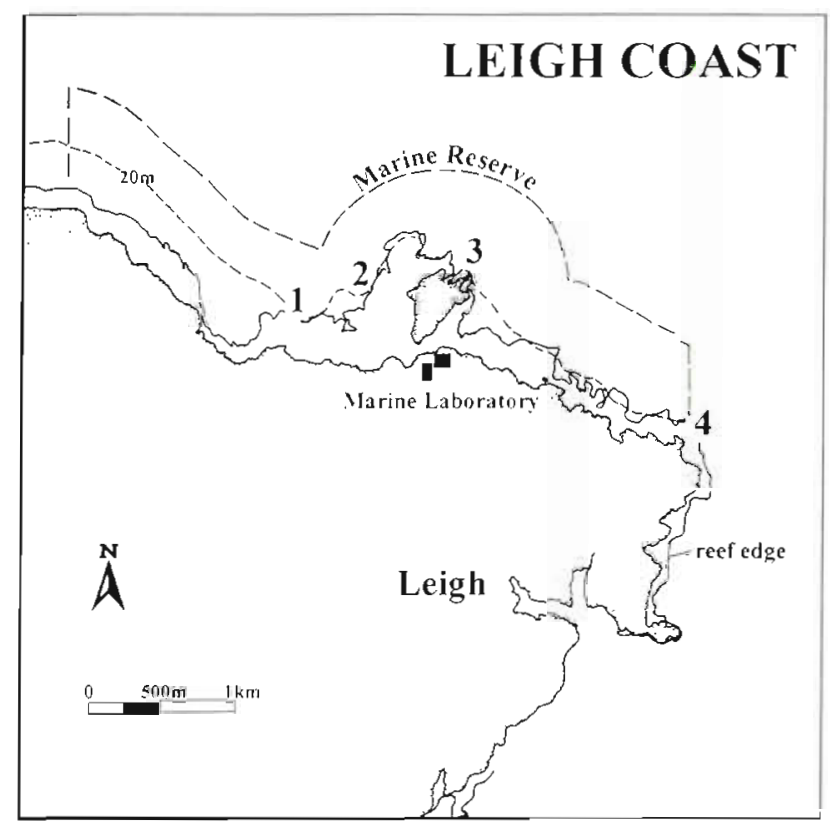

Fig. 1. The Cape Rodney to Okakari Point Marine Reserve showing the sites used in the distribution and abundance survey. Sites 1, 2, 3 and 4 represent Martins Rock, Sponge Garden, Splendid Reef and Cape Rodney respectively 
A preliminary visual survey within the Marine Reserve in 1991 revealed that Octopus tetricus occurred at sites with either of the 2 rock types. On the basis of this survey, 4 sites were chosen for the main part of this study: 2 in areas of sandstone (Martins Rock and Sponge Garden) and 2 in areas of greywacke (Splendid Reef and Cape Rodney) (Fig 1). Each site was composed of continuous bedrock to a depth of approximately 20 to $24 \mathrm{~m}$. Within these study sites 3 reef types were identified. 'Patch reef' consisted of reef and cobbles interspersed with sand; 'broken reef' consisted of continuous reef characterised by highly dissected bedrock; 'flat reef' consisted of continuous reef with characteristically little to no dissection. Patch and broken reefs were found at all sites, but flat reef was only found at Martins Rock and Sponge Garden. These habitats were found at a variety of depths. Depth classes were not consistent across sites however, and depth was treated as a covariate rather than a stratum.

Sampling design. In order to detect site, habitat, and temporal differences in abundance of octopus a 3-factor design was employed, with depth as a covariate. The habitat types in each site were sampled at 4 time intervals during 1992 (January-March, AprilJune, July-September, October-December) corresponding to the period from austral summer to the following spring. Sampling effort was allocated evenly within 3 depth strata to ensure that all reefal habitat types present at a site were sampled and subsequent inter-site comparisons were unbiased. Five replicate transects were sampled in each of the habitat types within each depth strata.

Sampling procedures. Strip-transects were used to quantify octopus density. A $50 \times 10 \mathrm{~m}$ strip-transect was chosen as the sampling unit. Early trials indicated that smaller transects yielded too many zero values and larger transects were logistically unfeasible due to time constraints. Five replicate $50 \times 10 \mathrm{~m}$ transects were laid out haphazardly, without overlap, within each habitat and depth category at all 4 sites. All transects were sampled using SCUBA, between the hours of 09:30 and 17:00. A sinusoidal search path was taken, so that all potential hiding places could be examined. All holes and crevices not fully visible were more closely inspected. Water visibility greater than $1.5 \mathrm{~m}$ was a prerequisite for all sampling.

Three reefal habitat variables were measured within each transect: depth; distance shoreward from edge of reef; mean number of small $(<30 \mathrm{~cm})$ boulders. Distance shoreward from edge of reef was measured, in metres, from the central point of a transect to the nearest reef/sand interface. Small boulders were counted in $10 \times 0.75 \mathrm{~m}^{2}$ quadrats randomly placed in the transect. Numbers of 3 reefal predator or prey species (crayfish, morays and conger eels) in the tran- sect were also recorded. Due to low octopus abundance at times other than summer, no habitat variables or predator-prey numbers were measured during autumn, winter or spring. All octopus located during this study were, where possible, sexed and where eggs were present brooding was recorded. The debris around octopus shelters (referred to as middens) was inspected, with prey species recorded as present or absent.

Octopus sheltering within the transect area were never observed to leave their shelter due to the presence of either the transect tape or the observer, so disturbance is assumed to be minimal. Sheltering octopus tolerated 'gentle' physical manipulation to determine sex and the presence of eggs. However, more than 'gentle' manipulation resulted in all octopus (except brooding females) vacating the area by the next day, rarely returning. Physical removal of an octopus from its shelter often resulted in attack by nearby fish, and refusal of the octopus to re-enter the shelter. To avoid movement of octopus between replicates, habitats, depths, and possibly sites, disturbance was kept to an absolute minimum while sampling. This minor disturbance did not appear to cause much stress.

The time taken to locate individuals of Octopus tetricus sheltering in the predominantly broken habitats improved with observer experience. Practice counts were made prior to sampling. Octopus often recoil slightly as the observer approaches, and this movement is easily recognised by an experienced observer. Additionally, the orange colouration of arms, funnel and mantle opening and the mound of shell debris commonly found outside shelters aided in locating individuals.

Sampling accuracy was assessed using 5 replicate transects within each habitat type at Sponge Garden. Octopus within each transect were counted by me, immediately followed by re-examination of the entire transect by me and 2 additional observers. No additional octopus were ever recorded. It is therefore assumed that the counting procedure was sufficiently accurate to enable site and habitat comparisons.

Shelter. The association of Octopus tetricus with shelter, within each habitat type, was examined relative to the sex and brooding status of each animal. Association was measured by classifying the type of shelter occupied by each octopus, and the position within each shelter of all octopus encountered during the summer survey. Three 'position' categories were defined relative to how far withdrawn into the shelter the octopus was (i.e. at the entrance, fully inside, or completely barricaded within the shelter). 'Barricaded' shelters had the entrance blocked by the addition of small boulders and debris. Observations from other seasons were not included to reduce possible seasonal 
differences. Few animals were recorded on the reef after summer.

Shelters were classed in 4 categories according to their degree of modification. 'Unmodified shelters' were defined as naturally formed holes or crevices, with no sign of either excavation or small boulderstacking. 'Excavated shelters' were those, generally associated with sand, that had been clearly deepened by digging sediment away from reef, but were devoid of boulders. 'Boulder-added shelters' were fortified with small boulders at the entrance of the shelter, with no signs of excavation. 'Excavated/boulder-added shelters' were those that were excavated, and fortified with small boulders. All octopus were found in shelters.

Sex and brooding classification. Each octopus encountered in the survey was gently manipulated to determine sex and brooding status. Males were distinguished from females by the presence of the spermatophoral groove on the third left arm. The spermatophoral groove is a more effective sex character than the hectocotyl, which is small in this species and generally well protected. All shelters were inspected for eggs by gently pushing the occupant back into its shelter-Octopus tetricus lays many obvious eggstrings. The presence of eggs characterised brooding females. Some animals could not be sexed due to the degree of disturbance this would entail. Pilot studies indicated that both non-brooding females and males occupied this category in approximately even proportions, but excess disturbance left the animals very vulnerable to predation strikes from fish. These octopus are not included in the histograms, but they were generally in the boulder-modified and excavated habitat types. The degree of sexual bias inherent in the final survey is unclear.

Analysis. Assumptions of Analysis of Variance (ANOVA) were tested by residual analysis. Taylor's power plot indicated the optimal data transformation was the square root. This transformation did not significantly reduce the variance-mean relationship however, so I have presented analyses of the raw data for ease of interpretation. Distribution and abundance data were analysed as linear models using the General Linear Model (GLM) procedure in SAS (SAS Institute 1987). Habitat classes were not found across all depths, but depth was suspected to exert an effect. Consequently, depth was initially included as a continuous covariate in an Analysis of Covariance (ANCOVA). Depth, however, did not alter the interpretation of the simple 3 way model, so the simple 3 way model is presented. The means, instead of the least squared means (corrected for the covariate), are presented for simplicity of interpretation. The final sample design was therefore a 3-way fixed factor ANOVA, with the factors 'Site', 'Habitat', and 'Season' fully crossed and fixed.
Habitat classes differed in several abiotic parameters. Patch reefs were usually at the base of the reef and thus were consistently deeper than other habitat types. Patch reef habitats were characterised by high numbers of small boulders. As a consequence, many of the physical parameters measured in this study were likely to be correlated with each other. In order to measure the unconfounded relationship between octopus abundance and reefal parameters at the finer-scale transect level, it was necessary to first partial out the effect of the other variables. Consequently, the relationships between octopus and abiotic and biotic reefal variables were analysed with partial regression and partial correlation. All residuals were calculated using the REG procedure in SAS. The partial regression plots are presented with a line of best fit, derived from the multiple regression analysis. As this model was descriptive rather than predictive, the partial correlations (analysed using the CORR procedure) were used to indicate the strength of the partialled relationship (SAS Institute 1987).

Two problems were apparent in the analysis of the shelter use data. Low sample sizes in some shelter categories precluded statistical analyses such as chisquare tests. More importantly, some of the row and column totals summed to zero-meaning that expected values for independence tests could not be calculated. As a partial test of independence, I treated the cells of any zero column or row total as structural zeros and ran a log-linear model as a test of independence. Results from this test should be viewed with caution, and interpretation should be based on the frequency histograms.

\section{RESULTS}

\section{Distribution and abundance}

Octopus tetricus densities differed between sites and habitats (Table 1). Season interacted with both site and habitat, with scattered individuals haphazardly appearing during seasons other than summer. The numbers of octopus contributing to these interactions were so low as to be biologically insignificant (see below). During summer, densities were higher at Splendid Reef $\left(\right.$ mean $=2.35 \pm 0.53$ per $\left.500 \mathrm{~m}^{2}\right)$ than Sponge Garden (0.75 \pm 0.23$)$, Martins Reef $(0.55 \pm 0.17)$, and Cape Rodney $(0.55 \pm 0.20)$. O tetricus densities were also higher in patch reef habitats $(2.20 \pm 0.37)$ than broken $(0.67 \pm 0.18)$ and flat reefs $(0.10 \pm 0.10)$ (Fig. 2). These habitat trends were consistent among study sites (Table 1). There was no relationship between habitat characteristics and sex of octopus (Fisher's exact test, $p=0.170$ ). 
Seasonal changes in octopus numbers were apparent at all sites, and all habitats (Table 1, Fig. 3), with greatest abundance (>90\% of years total) during summer. Abundance declined immediately following summer, becoming negligible during autumn and winter Slight increases in abundance were observed in spring, but numbers were still less than those of summer (Fig. 3). Qualitative observations early in the following summer (December 1993, and January 1994) confirmed that octopus numbers continued to increase. Brooding females were only observed between late spring and late summer (November to midApril). A total of 39 of the 42 females observed during the summer survey had clutches at some time during the summer Most eggs hatched in mid to late March. No brooding females were observed between mid-April and October, while only 5 nonbrooding individuals were found during these months. Qualitative observations early in the second summer (DecemberJanuary 1994) recorded 4 females, all brooding clutches.

No relationship between octopus densities and depth was found $(r=-0.075)$ after all other factors were partialled out (Fig. 4a). Octopus were more abundant at the reef edge, with abundance decreasing shorewards from the reef edge $(r=-0.436)$ (Fig. 4b). Abundance of octopus increased with increasing mean number of small boulders $(\mathrm{r}=0.354)$ (Fig. 4c). No relationship between octopus and either crayfish (I $=-0.044)$, moray eels $(r=-0.005)$, or conger eels $(r=0.125)$ was observed (Fig. 5). Patch reef habitats were closer to the reef edge than flat or broken reefs, with small boulders being more common in patch reefs than broken reefs. Flat reefs had very few if any small boulders (Table 2).

\section{Prey occurrence}

$69 \%$ of all octopus shelters contained middens, within which a wide variety of prey items (23 species from 4 taxa) were recorded (Fig. 6). $64 \%$ of all middens contained soft-sediment prey species $161 \%$ were soft-sediment bivalves and $3 \%$ miscellaneous soft-sediment species), while $36 \%$ of middens contained reefal prey spe-
Table 1. Octopus tetricus. 3-way ANOVA of octopus densities across sites, habitats, and seasons. ns: not significant

\begin{tabular}{|c|c|c|c|c|c|}
\hline Source & $\mathrm{df}$ & $\begin{array}{l}\text { Sum of } \\
\text { Squares }\end{array}$ & $\begin{array}{l}\text { Mean } \\
\text { Square }\end{array}$ & F-value & $\mathrm{p}$ \\
\hline Site & 3 & 13.5300 & 4.5100 & 10.99 & 0.0001 \\
\hline Habitat & 2 & 10.3292 & 5.1646 & 12.58 & 0.0001 \\
\hline Site $\times$ Habitat & 4 & 1.1658 & 0.2915 & 0.71 & $0.5855 \mathrm{~ns}$ \\
\hline Season & 3 & 54.14167 & 18.0472 & 43.97 & 0.0001 \\
\hline Site $\times$ Season & 9 & 38.16333 & 4.2404 & 10.33 & 0.0001 \\
\hline Habitat $\times$ Season & 6 & 27.5825 & 4.5971 & 11.20 & 0.0001 \\
\hline Site $\times$ Habitat $\times$ Seasor & n 12 & 5.5292 & 0.4608 & 1.12 & $0.3406 \mathrm{~ns}$ \\
\hline Error & 320 & 131.3333 & 0.4104 & & \\
\hline
\end{tabular}

Table 2. Mean (SE in parentheses) values of 3 physical variables of Octopus tetricus habitats in the Leigh Marine Reserve (patch reef $\mathrm{n}=20$; broken reef $n=60$; flat reef $n=10$

\begin{tabular}{|lccc|}
\hline Habitat & $\begin{array}{c}\text { Depth } \\
(\mathrm{m})\end{array}$ & $\begin{array}{c}\text { Distance shoreward } \\
\text { reef edge }(\mathrm{m})\end{array}$ & $\begin{array}{c}\text { No. of small } \\
\text { boulders }\end{array}$ \\
\hline Patch reef & $19.00(0.46)$ & $14.00(3.88)$ & $14.09(2.12)$ \\
$\begin{array}{l}\text { Broken reef } \\
\text { Flat reef }\end{array}$ & $12.09(0.72)$ & $90.67(7.02)$ & $5.50(0.69)$ \\
& $16.50(0.34)$ & $68.00(6.51)$ & $0.22(0.07)$ \\
\hline
\end{tabular}

a) Splendid Reef

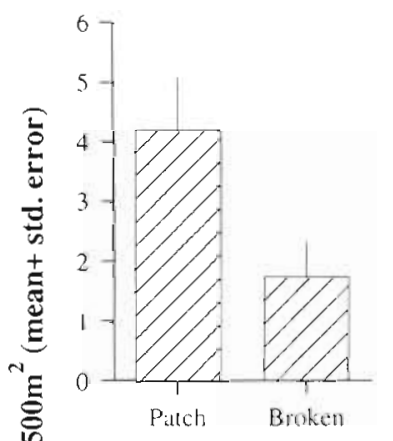

c) Sponge Garden

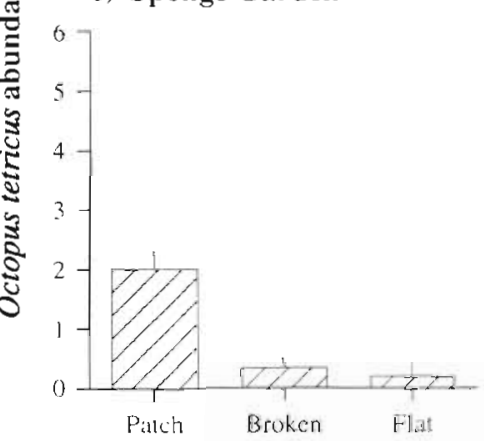

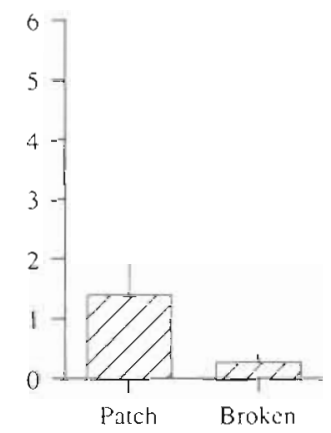

d) Martins Rock

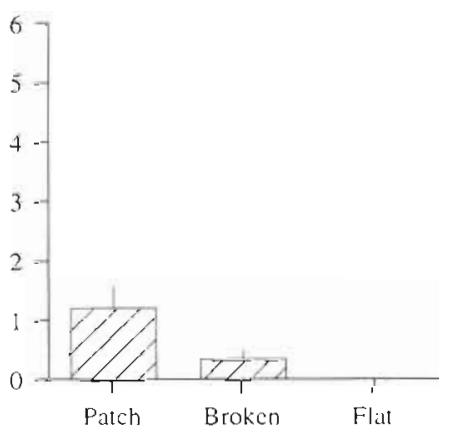

b) Cape Rodney

Habitat Type

Fig. 2. Octopus tetncus. Abundance during the summer survey in patch reef, broken reef, and flat reef habitats in 4 sites within the Cape Rodney to Okakan Point Marine Reserve 


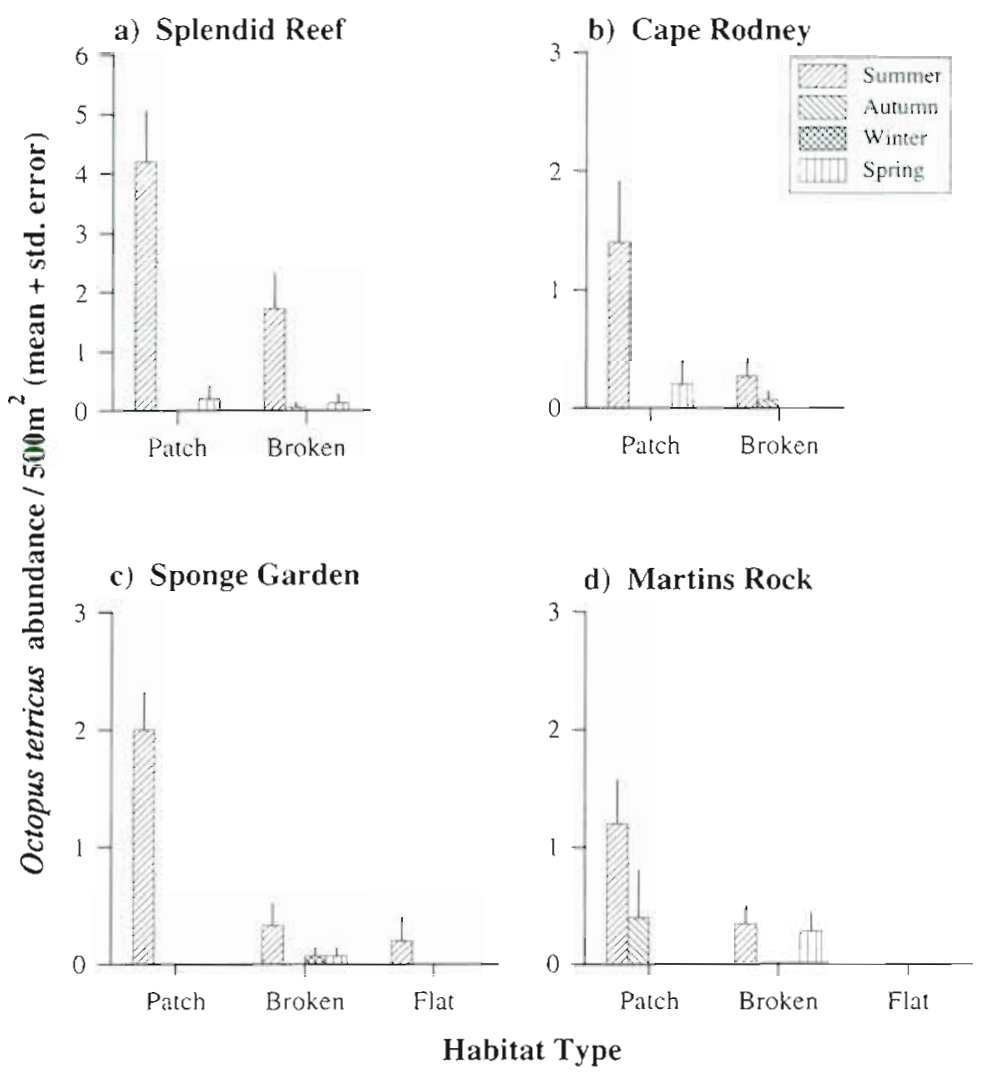

Fig. 3. Octopus tetricus. Temporal changes in abundance in patch reef, broken reef, and flat reef habitats in 4 sites within the Cape Rodney to Okakari Point Marine Reserve

cies (Fig. 6). The 3 most commonly found prey species were the dog-cockle, Glycymeris laticostata $(29 \%$ of all middens); scallops Pecten novaezealandica (13\% of all middens); and Dosinia spp. (10\% of all middens) (Fig. 6); all these species were found in adjacent softsediments. Generally reefal prey species, when present, were only recorded in low numbers. In contrast. soft-sediment prey species (particularly G. laticostata, $P$. novaezealandica, and to a lesser extent Dosinia spp.), when present, were invariably found in high numbers (author's pers. obs)

Given the constraints of this study, local distribution and abundance of soft-sediment prey species, such as Glycymeris laticostata, could not be addressed. However exploratory observations of adjacent soft-sediment habitat found $G$. laticostata to be common/abundant in areas where octopus were found, although the distance of beds away from the reef edge varied (author's pers. obs.).

\section{Shelter use}

The types of shelters occupied by octopus differed with habitat (log-linear model, 3-way interaction, $\chi^{2}=$
7.11, $\mathrm{p}=0.0077$ ). All octopus in patch reef habitats modified their shelters, while octopus in broken reefs were found in both small boulder-modified, and unmodified shelters (Fig. 7a). Octopus in patch reefs were frequently found in excavated shelters (Fig. 7 a). In contrast, no excavated shelters were found in broken reefs (Fig 7a).

Sex differences between and within habitats were apparent. Males were less likely to modify shelters in broken reefs than in patch reefs (Fig. 7 b), with unmodified shelters having little or no entrance debris. All 7 females found in patch reefs were in modified shelters (Fig. 7c). Of the 7 females found in broken reefs, 5 were in bouldermodified shelters, and 2 were in unmodified shelters (Fig. 7c). These patterns, however, are based on low numbers and should be treated with caution. Brooding females were never observed in unmodified shelters in either patch or broken reefs (Fig $7 \mathrm{~d}$ ), and were generally found in shelters where excavation and/or boulder modification was possible.

The position of animals in shelters also varied between sexes (log-linear model, 2 -way interaction, $\chi^{2}=63.11, p<0.0001$ ). Males, females, and brooding females were all commonly found inside shelters, although approximately $25 \%$ of males were seen at the entrances of very rudimentary shelters. No brooding females were ever found at the entrance of the shelter. Only brooding females barricaded shelter entrances (Fig. 8).

\section{Life cycle}

No Octopus tetricus recruits or juveniles (less than $400 \mathrm{~g})$ were found on coastal reefs during this study. Anecdotal accounts from commercial and scientific scallop dredgers indicated that recruits and juvenile $O$. tetricus were frequently found in outer Hauraki Gulf soft-sediment habitats directly offshore $(50 \mathrm{~m}$ to $3 \mathrm{~km}$ from the coast) at depths ranging from $18 \mathrm{~m}$ to the deepest samples at $45 \mathrm{~m}$ (authors' pers. obs., M. A. Morrison pers. comm.). Juvenile $O$. tetricus were most frequently caught during June, July and August; however no dredge samples were available between midDecember and mid-February. Dredged octopus ranged in size from $0.5 \mathrm{~g}$ to $333 \mathrm{~g}$, and were commonly collected from 3 soft-sediment habitat types-shell gravel with abundant hermit crabs; horse mussel 

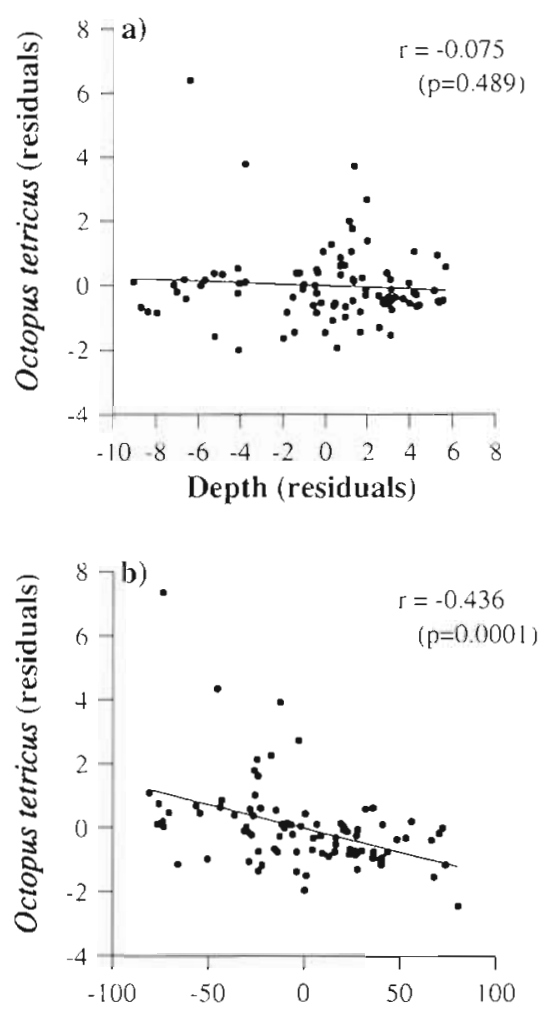

Distance from edge of reef (residuals)

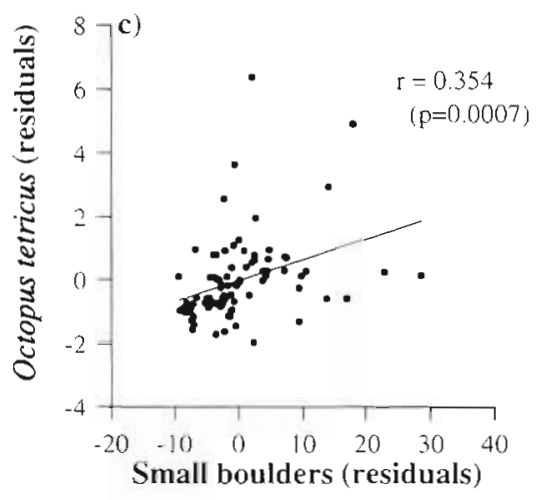

Fig. 4. Octopus tetricus. Partial regression plots of octopus abundance on physical variables during the summer survey. Slopes are derived from the full multiple regression model $r$ is the partial correlation coefficient with its associated significance test. (a) Partial relationship between octopus abundance and depth. (b) Partial relationship between octopus abundance and distance from edge of reef. (c) Partial relationship between octopus abundance and number of boulders

(Atrina pectoralis) beds; and scallop (Pecten novaezealandica) beds with shell gravel.

Adults were rarely collected in scallop dredges, but were caught locally in the outer Hauraki Gulf by commercial fishermen. No quantitative catch data were available as octopus are a nuisance bycatch in crayfish
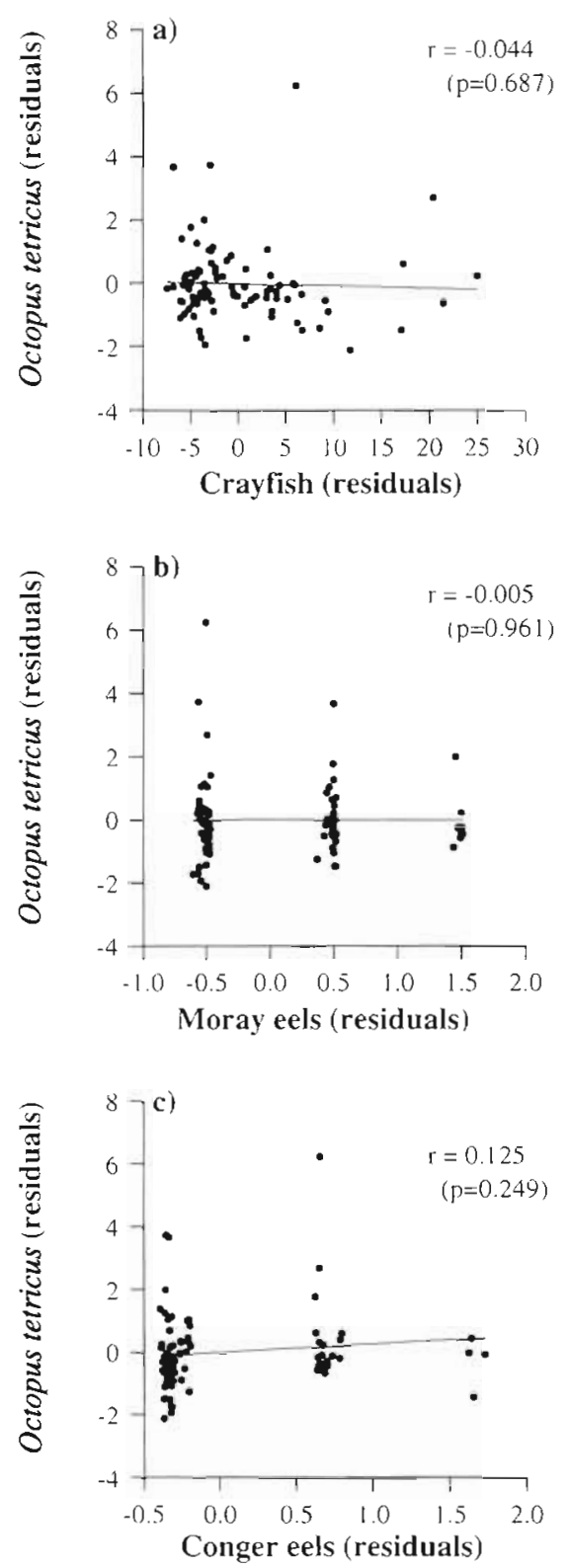

Fig. 5. Octopus tetricus. Partial regression plots of octopus abundance on potential predator and prey abundances during the summer survey. Slopes are derived from the full multiple regression model; $r$ is the partial correlation coefficient with its associated significance test. (a) Partial relationship between octopus abundance and crayfish abundance. (b) Partial relationship between octopus abundance and moray eel abundance. (c) Partial relationship between octopus abundance and conger eel abundance

pots and on longline hooks, and are regularly not landed. These methods of fishing are conducted throughout the year. Anecdotal observations from commercial fishermen indicate that catch rates are highest in late spring and summer, abruptly dropping at the end of summer. 


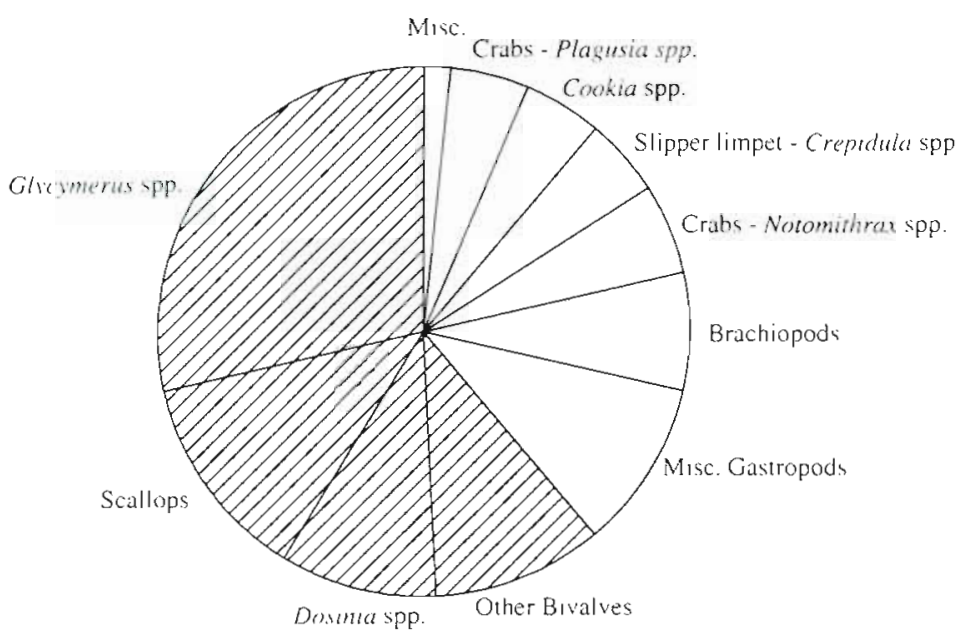

Fig. 6. Percent occurrence of Octopus tetricus prey species within all shelter middens. Shaded portions refer to soft-sediment prey species. Non-shaded portions reter to reefal prey species

\section{DISCUSSION}

This study provides one of the first detailed insights into the demographic patterns of reefal octopus. Despite the potentially important role octopus have on the reef, habitat use by octopus has received limited attention (but see Ambrose 1982, 1988, Mather 1982b, Hartwick et al. 1984a, Aronson 1989). In this study, I used a relatively simple but rigorous transect method and found temporal, spatial, and large scale habitat differences in abundance of Octopus tetricus. In addition octopus were associated with fine scale physical features, while no association with potential reefal predator or prey species was found. Octopus appeared to favour specific shelter types, but this varied with habitat type and brooding status.

\section{Spatio-temporal dynamics}

All sites studied were similar in their habitat availability and depth range, yet octopus were patchily distributed across sites. Octopus were 3 to 4 times more abundant on Splendid Reef than the other sites. This difference did not appear to be related to substratum type-Splendid Reef and Cape Rodney were composed of greywacke, while Sponge Garden and Martins Reef were composed of sandstone. Site-specific differences in Pacific octopus (Octopus dofleini martini) abundance have been demonstrated, and found to be consistent over time (Hartwick et al. 1984a). An expanded tempo$\mathrm{ral}$ and spatial sampling programme will be required to determine if this is true for $O$. tetricus also.

Densities differed among habitats, and these differences were consistent across sites. Octopus were 2 to 3 times more abundant in patch reef habitat than broken reef, and were rarely found on flat reefs. Previous studies in the Bahamas (Octopus briareus, Aronson 1986, 1989) and in northern Florida, USA (O. joubini, Mather 1982a), which focused on octopus densities within patch reef habitats, reported much higher numbers ( 4 and 15 per $500 \mathrm{~m}^{2}$, respectively) than those reported in this study (2.2 per $500 \mathrm{~m}^{2}$ in patch reef habitat). Low densities in this study may reflect specific differences, but it is also possible that high densities in the previous studies were the result of biased site selection and non-replicated density estimates. In Mather. (1982a) density estimates were incidental to the main study in which areas of high octopus densities were deliberately chosen. The greatest density of $O$. tetricus recorded during the present study was 6 individuals in a $150 \mathrm{~m}^{2}$ area (i.e. 20 per $\left.500 \mathrm{~m}^{2}\right)$. This value is higher than that found by Mather (1982a) and clearly highlights the need for formal random sampling to obtain unbiased estimates of the population for comparative purposes.

Octopus abundance varied over time across all sites and habitats. Adult Octopus tetricus were abundant on coastal reefs in summer, and all but disappeared from the reef prior to the second week of April lonset of autumn) The exceptions were 2 immature females (both smaller than $1000 \mathrm{~g}$ ). As this study was limited to $1 \mathrm{yr}$, it is premature to class this as an annual pattern, but qualitative observations in the subsequent summer (December 1993, and January 1994) indicated that octopus numbers increased. $O$. tetricus is also caught locally in the outer Hauraki Gulf by commercial fishermen as a bycatch in crayfish pots and on longline hooks, with catch rates highest in late spring and summer, abruptly dropping at the end of summer. Seasonal peaks in abundance during summer, followed by precipitous declines, have been recorded for several other species (O. vulgaris, Mangold-Wirz 1963, Mangold 1983; O. briareus, Aronson 1986, 1989; O bimaculatus, Ambrose 1988). To determine if this is an annual pattern, longer term monitoring is required. The temporal patterns presented in this study may not be found in all members of the population. For example, I observed many immature animals on the reef during the winter of 1992-often in high densities (approx 5 per $500 \mathrm{~m}^{2}$ ). Additionally, Ambrose (1988) found that high abundances of octopus in autumn were attributable to an influx of juveniles into the area. Ambrose found this pattern was consistent for 2 out of 6 years. Clearly, population size structures and reproductive status of individuals on reefs should be recorded to decipher different abundance patterns in mature and immature individuals. 

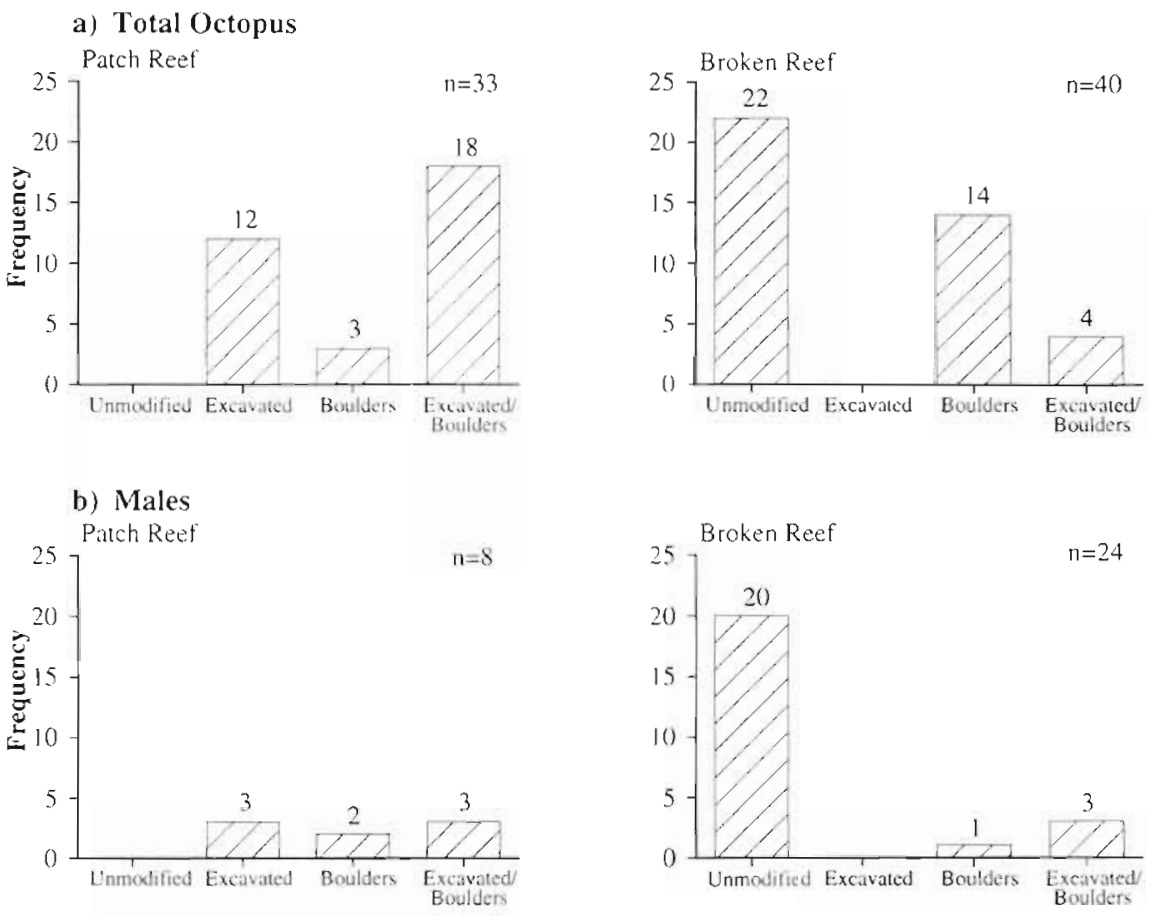

Fig. 7 Frequencies of type of shelter modification by Octopus tetricus in Patch Reef and Broken Reef habitats during the summer survey. Data are pooled across sites, for all octopus that were able to be sexed
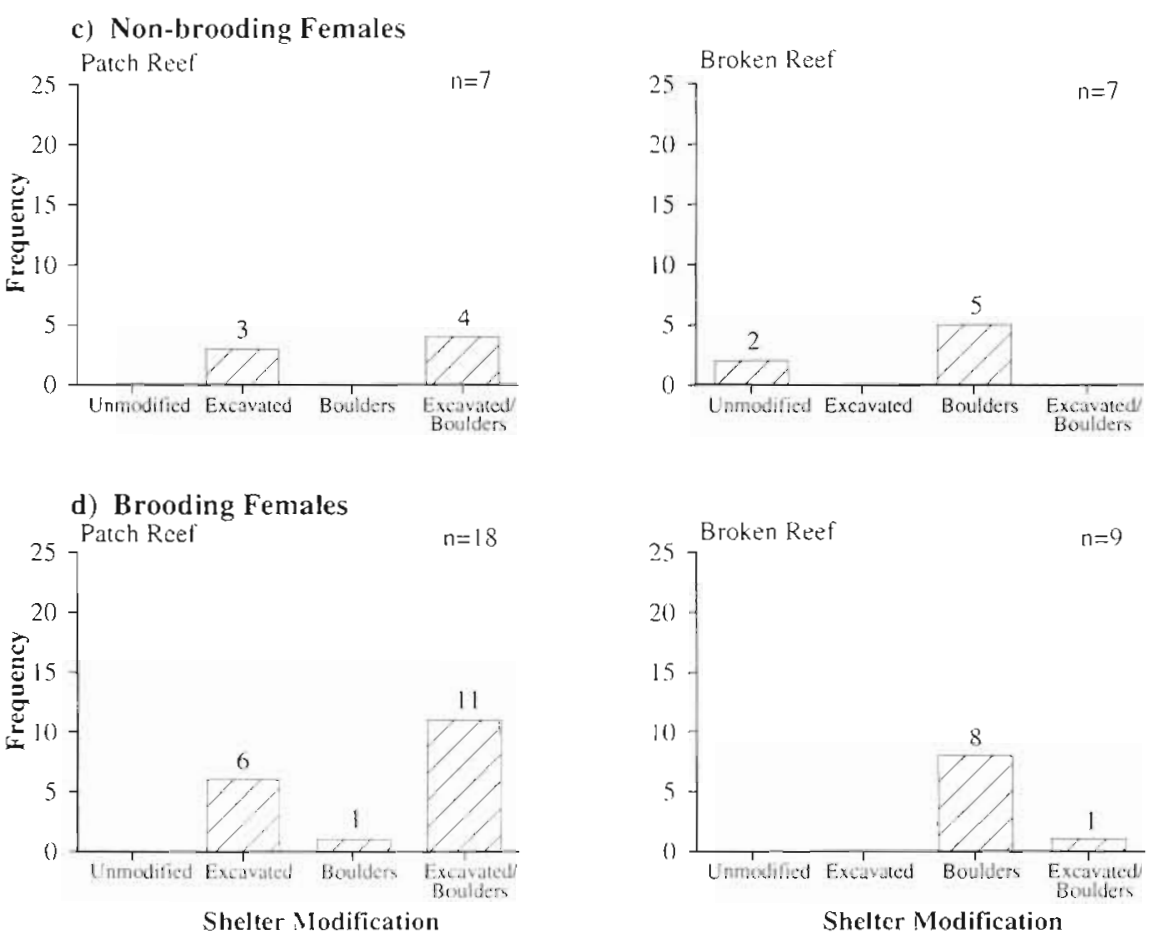

\section{Habitat association}

No relationships between octopus and potential reefal predators (moray or conger eels) or predator/ prey (crayfish) were found, although crayfish, moray and conger eels were commonly found in the same transects. Soft-sediment bivalves, particularly Gly- cymeris laticostata, Pecten novaezealandica, and Dosinia spp., occurred in the majority of shelter middens, suggesting that octopus foraged over adjacent soft-sediments rather than on the rocky reef itself. It is apparent that reefal prey-predator distributions alone are not sufficient to explain patterns of reefal habitat use. Given the wide variety of possible prey species, 
a) Males

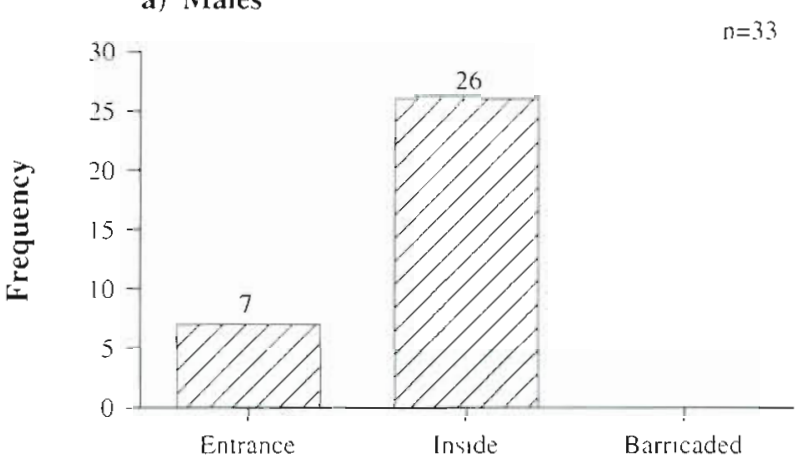

b) Females

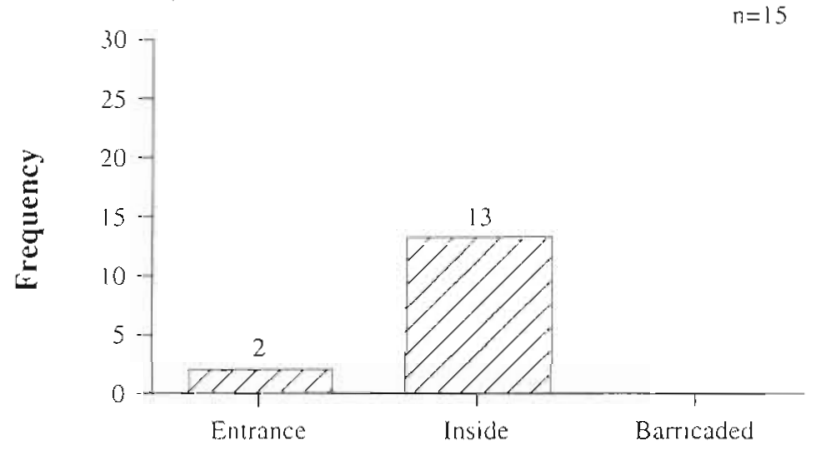

c) Brooding females

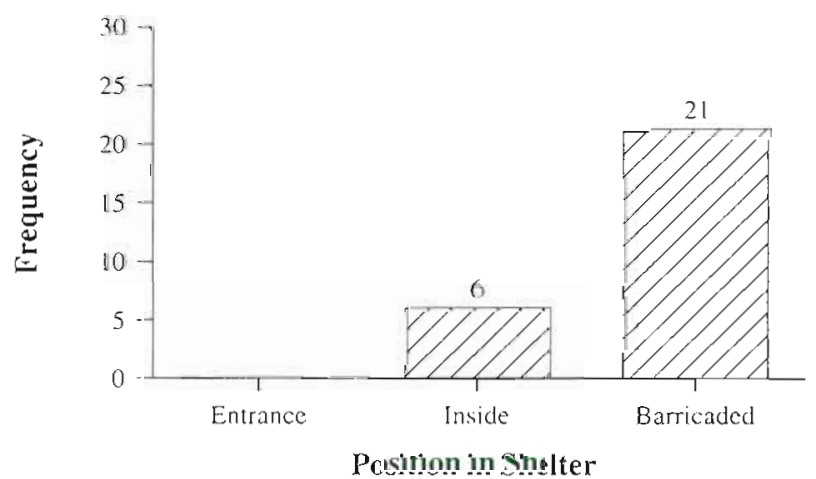

Fig. 8. Octopus tetricus. Frequencies of position within shelter of males, females, and brooding females during the summer survey. Data are pooled across sites and habitats

and that octopus are highly mobile and able to forage a considerable distance away from shelter areas (but see Mather \& O'Dor 1991), determining the spatial relationship between octopus and prey is likely to be difficult. Octopus were found in highest numbers at the reef edge, decreasing with distance shoreward, and in areas with high numbers of small boulders. Octopus on the reef edge would be closer to soft-sediment food sources, thus reducing foraging time and energy. Soft-sediment prey distributions may be an important factor in determining habitat use at the scale of the rocky reef
Shelter use

Octopus are highly mobile and sensory animals, and are likely to be able to exert considerable choice in which shelter they occupy. Octopus tetricus appear to modify shelters where possible, and when given the choice, will select shelters that provide the best protection (Mather 1982a, Hartwick et al. 1984b. Aronson 1986, Voight 1992). Modified shelters were frequently occupied in both patch and broken reefs, but the degree of modification varied between habitats. In patch reef habitats, all octopus were found in modified shelters. In broken reefs, however, brooding females were always found in modified shelters, but males and non-brooding females were frequently found in unmodified shelters. Patch reef habitat generally consisted of reef and sand, often with overlying boulder rubble. The combination of these malleable features allowed for modification by either excavation of sand or addition of small boulders around the entrance of the shelter, or both. Broken reef habitat consisted of solid continuous bedrock, and unlike patch reef habitats rarely allowed excavation. Habitat type, therefore. may restrict the degree of modification possible.

The position of octopus within the shelter varied between sexes. Males, and to a lesser extent nonbrooding females, were commonly found exposed at the shelter's entrance. In contrast, all brooding females were found either deep inside excavated shelters or within partially to completely barricaded shelters regardless of the habitat type. Barricaded brood shelters have also been observed for several other species (e.g. Octopus vulgaris, Wodinsky 1972; O. bimaculatus, Ambrose 1988), and may be common in shallowbenthic species.

Differences in shelter use between sexes and brooding status are likely to be a result of the changing needs between a predominantly mobile foraging existence and one of constant care and protection of eggs (see Mangold 1983, Van Heukelem 1983). This is exemplified by the increased barricading of the 'brood' shelter by females, approximately 1 to $2 \mathrm{wk}$ prior to egg laying (author's pers. obs.). Females cease to forage, feed or mate during this period (Wells 1978, Wodinsky 1978, Ambrose 1981, author's pers. obs.), and presumably do not require an open entrance at this time. Field observations and published accounts indicate that brooding-females and their clutches may be under considerable predation pressure from both conspecific and congeneric males (author's pers. obs.), and other animals such as moray eels (Ambrose 1988) and fish. Availability of barricading material and modifiability of the shelters may constitute a key factor in determining the abundance of brooding females within a habitat. 
The ability to modify a shelter may increase shelter availability. Modification of shelter cavities by blocking with boulders would allow small octopus to reduce the exposure/entrance diameter of a larger shelter. allowing a closer fit and better protection (Mather 1982a, Aronson 1989). Alternatively, the ability to excavate would allow a large octopus to enlarge and subsequently occupy a significantly smaller shelter. Without the ability to modify, octopus would be limited to shelters that were of a similar size to themselves. Consequently, shelters may be limiting in unmodifiable habitats, especially for large sized animals (see Hartwick et al. 1984b)

\section{Synthesis}

This study, although preliminary, has demonstrated that the ecology of habitat use of Octopus tetricus is both complex and dynamic. Adult $O$. tetricus were abundant on the reef during summer and all but disappeared from the reef in the first weeks of autumn. Octopus numbers remained negligible until the following summer. Unlike the adults, juvenile octopus were not found on coastal reefs, but were frequently dredged from soft-sediment habitats. These patterns of habitat separation between pre-adult and adult populations indicated a likely inshore movement on to the reef-a hypothesis which should be tested in future studies

If ontogenetic habitat shifts are indeed a feature of Octopus tetricus ecology, this would raise some interesting hypotheses. Movement of adults inshore may be a result of either larger sized prey becoming limiting in soft-sediment habitats, or a change in dietary requirements. This is unlikely as octopus in soft-sediment habitats already have a wide size-range of prey to select from. Additionally, adult $O$. tetricus on reefal habitats continued to feed on soft-sediment bivalves, including Glycymeris laticostata, Pecten novaezealandica, and Dosinia spp.

Movement may be the result of appropriately sized shelters becoming limiting (Ambrose 1988). Juvenile octopus in soft-sediment habitats sheltered in empty bivalve and gastropod shells, which are small and can only be occupied by small animals. As octopus outgrow these shells, they may move in search of new shelter, i.e. the nearest reefal habitat. Octopus maorum (Hutton, 1880), another large shallow-water benthic species, are also commonly found in soft-sediment habitats, suggesting that shelter is not strictly limiting for large Octopus species (author's pers. obs.). It is unlikely that population movement inshore would result solely from shelter limitation.

This study indicates that inshore movements during spring and early summer may be motivated by breed- ing. Most female Octopus tetricus on the reef brooded egg clutches during summer. At this time, all males were sexually mature with $>90 \%$ of individuals primed with sperm (sperm sac full, and sperm protruding from penis), and several mating interactions were observed (author's pers. obs.). Inshore spawning migrations have been documented for several octopus and squid species (see references in Boyle 1983b). These hypotheses are not likely to be mutually exclusive, but may be addressed with appropriate experimentation.

Several processes operating at a range of scales are likely to influence octopus spatial abundance patterns. This study has provided an initial insight into Octopus tetricus ecology, identifying several hypotheses for further examination. $O$. tetricus appears to have a complex life cycle. The reefal stage of its life appears dominated by breeding requirements, e.g. shelter material availability. A large part of the life of $O$. tetricus may be spent off the reef-presumably on soft-sediments. By providing an energetic 'link' between 2 distinct types of habitat, $O$. tetricus is quite unusual among benthic marine invertebrates and its ecology deserves further examination.

Acknowledgements. I thank all those who helped in the field, especially Simon Parr, A.lan Duckworth, Chris Battershill and Mark Morrison. I also thank Craig Syms and Brian McArdle for statistical advice. Comments on various forms of the manuscript were made by Ross Alford, Chris Battershill, Bob Creese, Mark McCormick, Craig Syms, and an anonymous reviewer. This paper is a contribution from the University of Auckland, Biological Sciences Department and the University of Auckland's Leigh Marine Laboratory.

\section{LITERATURE CITED}

Ambrose RF (1981) Observations on the embryonic development and early post-embryonic behaviour of Octopus bimaculatus. Veliger 24:139-146

Ambrose RF (1982) Shelter utilisation by the molluscan cephalopod Octopus bimaculatus. Mar Ecol Prog Ser 7: $67-73$

Ambrose RF (1984) Food preferences, prey availability, and the diet of Octopus bimaculatus Verrill. J Exp Mar Biol Ecol 77:29-44

Ambrose RF (1988) Population dynamics of Octopus bimaculatus: influence of life history patterns synchronous reproduction and recruitment. Malacologia 29:23-39

Anderson TJ (1994). Taxonomy and cology of shallowbenthic octopus in north-eastern New Zealand. MSc thesis, University of Auckland

Aronson RB (1986) Life history and den ecology of Octopus briareus (Robson) in a marine lake. J Exp Mar Biol Ecol 95: $37-56$

Aronson RB (1989) The ecology of Octopus briareus (Robson) in a Bahamian saltwater lake. Am Malacol Bull 7:47-56

Ayling AM (1978) Okakari Point to Cape Rodney Marine Reserve: a biological survey. Report, University of Auckland 
Ayling AM (1981) The role of biological disturbance in temperate subtidal encrusting communities. Ecology 62:830-847

Boyle PR (1983a) Eledone cirrhosa. In: Boyle PR (ed) Cephalopod life cycles, Vol I, Species accounts. Academic Press. London, p 365-386

Boyle PR (ed) (1983b) Cephalopod life cycles, Vol I, Species accounts. Academic Press, London.

Choat JH, Schiel DR (1982) Patterns of distribution and abundance of large brown algae and invertebrate herbivores in subtidal regions of northern New Zealand. J Exp Mar Biol Ecol 60:129-162

Gordon DP, Ballantine WJ (1976) Cape Rodney to Okakari Point Marine Reserve: review of knowledge and bibliography to December (1976). Tane 22 (Suppl):1-146

Hartwick EB, Ambrose RF, Robinson SMC (1984a) Dynamics of shallow-water populations of Octopus dolfleini Mar Biol 82:65-72

Hartwick EB, Ambrose RF, Robinson SMC (1984b) 1)en ut1lization and the movements of tagged Octopus dolicini. Mar Behav Physiol 11:95-110

Hartwick EB, Robinson SMC, Ambrose RF, Trotter D, Walsh $M$ (1988) Inshore-offshore comparisons of Octopus dofleini with special reference to abundance growth and physical. conditions during winter. Malacologia 29:57-68

Hartwick EB. Thorarinsson G (1978) Den associates of the giant Pacific octopus Octopus dofleini (Wülker). Ophelıa 17:163-166

Hartwick EB, Thorarinsson G, Tulloch L (1978b) Antipredator behaviour in Octopus dolfleinj (Wülker). Veliger 21: $263-264$

Hartwick EB, Tulloch L, MacDonald S (1981) Feeding and growth of Octopus dofleinı (Wülker). Veliger 24:129-138

Mangold K (1983) Octopus vulgarss. In: Boyle PR (ed) Cephalopod life: cycles, Vol I, Species accounts. Academic Press, London, p 335-364

Mangold-Wirz K (1963) Biologie des céphalopodes benthiques et nectoniques de la Mer Catalane. Vie Milieu (Suppl) 13:1-285 (translated summary only)

Mather JA (1982a) Choice and competition: their effects on

This article was submitted to the editor occupancy of shell homes by Octopus joubinu. Mar Behav Physiol 8:285-293

Mather JA (1982b) Factors affecting the spatial distribution of natural populations of Octopus joubini Robson. Anm Behav 30:1166-1170

Mather JA (1988) Daytime activity of juvenile Octopus vulgaris in Bermuda. Malacologia 29:69-76

Mather JA (1992) Interactions of juvenile Octopus vuigaris with scavenging and territorial fishes. Mar Behav Physiol 19:175-182

Mather JA, O'Dor RK (1991) Foraging strategies and predation risk shape the natural history of juvenile Octopus vulgaris. Bull Mar Sci 49:256-269

McCormick MI, Choat JH (1987) Estimating total abundance of a temperate-reef fish using visual strip transects. Mar Biol 96:469-478

Russcll BC (1971) Ecological relationships of rocky reef fishes of north-eastern New Zealand. MSc thesis, University of Auckland

SAS Institute (1987) SAS/STAT ${ }^{\text {TM }}$ guide for personal computers, Version 6 edn. SAS Institute Inc, Cary, NC

Van Heukelem WF (1983) Octopus cyanea. In: Boyle PR (ed) Cephalopod life cycles, Vol I, Species accounts. Academic Press, London, p 267-276

Voight JR (1988) A technique for trapping sandflat octopuses. Am Malacol Bull 6(1):45-48

Voight JR (1992) Movement injury and growth of members of a natural population of Pacific pygmy octopus Octopus digueti. J Zool, Lond 228:247-263

Wells MJ (1978) Octopus: physiology and behaviour of an advanced invertebrate. Chapman and Hall, London

Wodinsky J (1969) Penetration of the shell and feeding on gastropods by Octopus. Am Zool 9:997-1010

Wodinsky J (1972) Breeding season of Octopus vulgaris. Mar Biol 16:59-63

Wodinsky J (1978) Feeding behaviour of broody female Octopus vulgaris. Anim Behav 26:803-813

Yarnell JL (1969) Aspects of the behaviour of Octopus cyanea (Gray). Anim Behav 17:747-754

Manuscript first received: July 1, 1996

Revised version accepted: February 10, 1997 